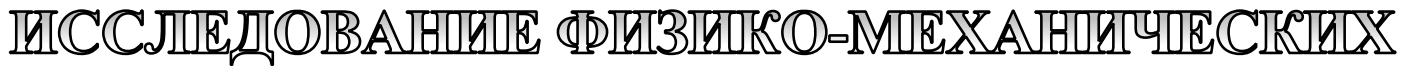

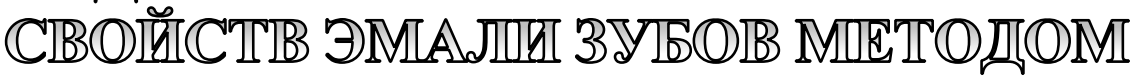

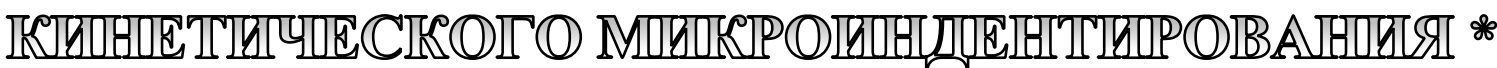

\author{
О.С. Гилева, Пермский государственный медицинский \\ университет им. академика Е.А. Вагнера \\ А.Д. Левицкая, Пермский государственный медицинский \\ университет им. академика Е.А. Вагнера \\ А.Л. Зуев, Институт механики сплошных сред УрО РАН
}

\section{Для цитирования:}

Гилева О.С., Левицкая А.Д., Зуев А.Л. Исследование фииико-механических свойств эмали зубов методом кинетического микроиндентирования // Вестник Пермского федерального исследовательского центра. - 2021. - № 1. - С. 37-46. https://doi.org/10.7242/2658-705X/2021.1.3

Проведена сравнительная оценка фризико-механических свойств зубной эмали: здоровой; деминерализованной; деминерализованной и впоследствии проинфильтрированной жидкотекучим композитом по стандартной, модифицированной и комбинированной методике, завершаемой ламинированием проинфильтрированной эмали биоактивным гибридным стеклоиономером. Для исследования использована оригинальная in vitro модель искусственного кариеса эмали зубов человека, клиникотопографические и цветотекстурные ффизико-механические свойства которого соответствуют характеристикам кариеса эмали in vivo. Сравнительный анализ результатов кинетического микроиндентирования образцов эмали позволяет охарактеризовать биоматериал с позиций физического материаловедения, определить преимущества и недостатки различных технологических вариантов инфильтрационного лечения кариеса (очаговой деминерализации) эмали.

Ключевые слова: очаговая деминерализачия эмали, искусственный кариес эмали, инфильтрачионное лечение, микроиндентирование эмали, микротвердость, модуль упругости.

\section{Введение}

Экспериментальная разработка и внедрение в лечебную практику инновационных технологий профилактики и лечения очаговой деминерализации эмали (ОДЭ) как ранней стадии кариеса зубов - важнейшая задача современной фундаментальной и клинической стоматологии $[4-9,14,16]$. Повышение эффективности инфильтрационного лечения ОДЭ, основанного на пассивной диффузии жидкотекучего композита (ЖТК) в микропорозную структуру деминерализованной эмали с его последующим световым отверждением, во многом

* Работа выполнена при поддержке Российского фонда фундаментальных исследований, Грант № 17-48-590562-р_урал_а. 
связывают с улучшением физико-химических свойств инфильтранта, в частности, его проникающей способности, а также с обеспечением оптимальной (по глубине и полноте) обтурации очага деминерализации ЖТК [10-11, 16, 19].

Механизмы возникновения, развития и прогрессирования кариеса эмали у пациентов многоплановы, справедливо рассматриваются с позиций изменения физико-механических свойств (микротвердость, упругость и т.д.) эмали под действием кариесогенных факторов риска, а также с учетом возникновения и распространения в ней зон напряжений и деформаций на границах очага поражения и интактной эмали [2-3, 13, 15, 17]. Для оценки физико-механических свойств эмали в норме, при различных заболеваниях или повреждениях твердых тканей зубов, а также в динамике различных лечебнопрофилактических воздействий с успехом применяются методы микро- или наноиндентирования $[1,12]$. Аттестация физикомеханических свойств эмали с оценкой возможности и особенностей её ремоделирования после проведения различных методик лечения требует применения оптимальных экспериментальных моделей искусственного кариеса эмали (ИКЭ), разработки адекватных способов их создания in vitro и соответствующего аппаратурно-технологического обеспечения, т.к. существующие методологические подходы не всегда универсальны $[15,18]$.

Цель исследования - в сравнительном аспекте изучить физико-механические свойства зубной эмали: здоровой; деминерализованной; деминерализованной и впоследствии проинфильтрированной жидкотекучим композитом по стандартной, модифицированной и комбинированной инфильтрационной методике, завершаемой ламинированием проинфильтрированной эмали биоактивным гибридным стеклоиономером.

\section{Материал и методы}

Материалом для экспериментального исследования физико-механических свойств эмали послужили 24 интактных зуба (первые и вторые премоляры верхней и нижней челюстей), удаленных по ортодонтическим показаниям. В исследование включали зубы с сохраненной коронкой и отсутствием видимых дефектов; предварительно зубы подвергали атравматичной механохимической обработке по оригинальной методике (рацпредложение № 2165 от 23.01.2001 «Методика подготовки биопрепаратов удаленных зубов», Гилева О.С. и соавт.).

ИКЭ моделировали на вестибулярной поверхности коронки, используя разработанное нами оригинальное аппаратурноинструментальное обеспечение: «Устройство для моделирования экспериментального кариеса в стадии пятна методом эмалевого окна» (патент на полезную модель № 172561 от 17.07.2017) и «Сепаратор для хранения биопрепаратов зубов с целью моделирования искусственного кариеса» (патент на полезную модель № 171409 от 30.05.2017), а также деминерализирующий гель оригинального состава (рацпредложение № 2757 от 17.05.2018): 3 г праестола 2510 (полиакриламид с молекулярным весом около 14 млн ед.), 8 мл 80\%-ной молочной кислоты, 0,4 г дигидрофосфата кальция, раствор гидроксида натрия 1 г в 10 мл воды (до $\mathrm{pH}$ раствора 4,5), дистиллированная вода - до объема 1000 мл. Этапы создания ИКЭ представлены на рис. 1.

Для высокоточного анализа физикомеханических свойств эмали в заданных экспериментом условиях использовали метод кинетического (непрерывного) микроиндентирования, основанный на проникновении индентора с известными физико-механическими свойствами и заданным усилием в изучаемую поверхность эмали. Кинетическое индентирование эмали проводили с помощью высокоточного прибора «Micro-combi tester» (MCT, CSM Instruments SA, Швейцария), оснащенного комбинированным модулем для микроиндентирования, автоматизированным предметным столиком (по осям X, Y, Z), преци- 


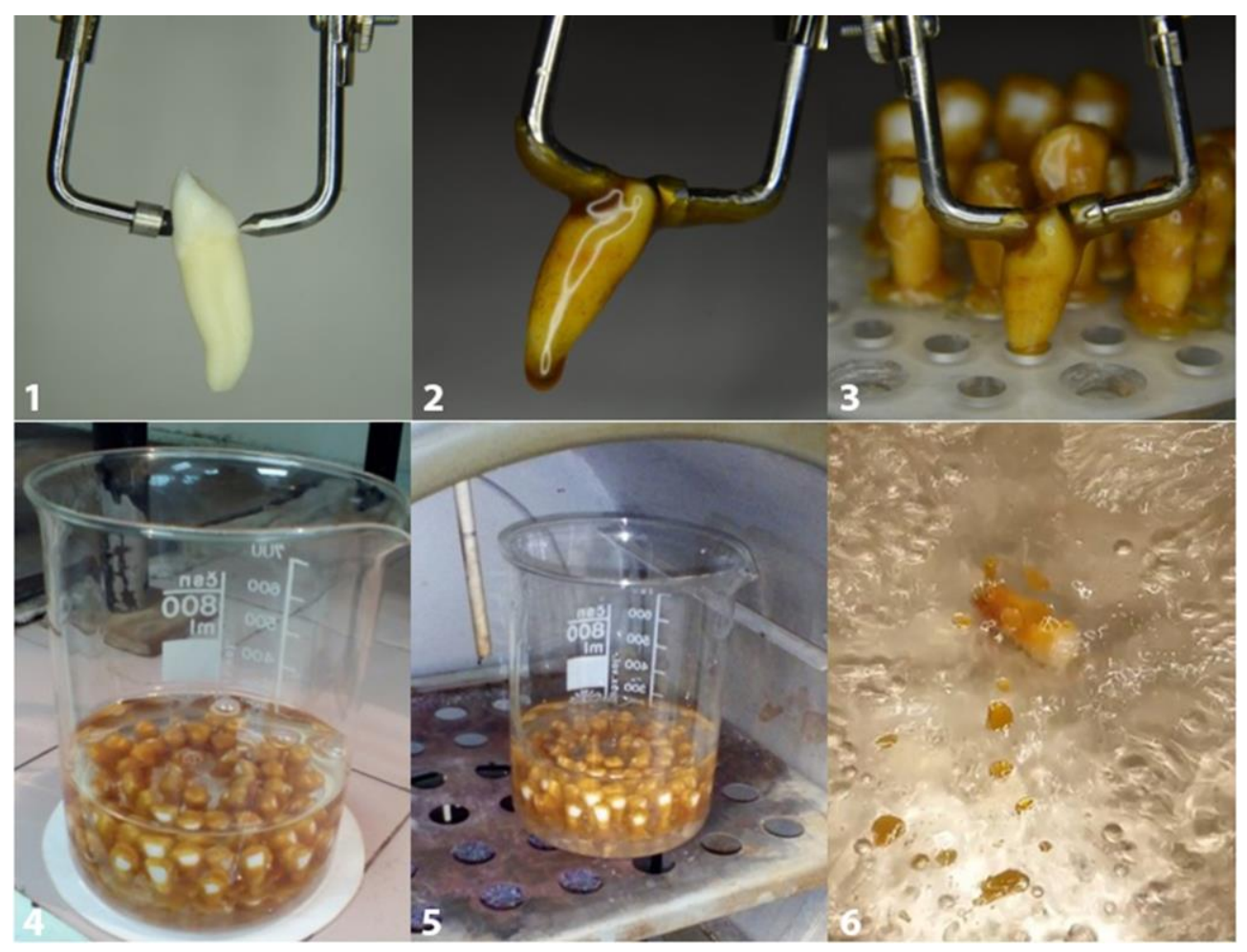

Рис. 1. 1-установка резинового формирователя в цеентре вестибулярной поверхности коронки по методу «эмалевого окна»; 2 - погружение образиа в растопленный липкий воск; 3 - установка

покрытых воском образиов в сепаратор; 4 - помещение сепаратора в лабораторный стакан

с деминерализирующим гелем; 5 - помещение в термостат при $\mathrm{pH}=4,5, t^{\circ}=37^{\circ} \mathrm{C}$ на 10 суток, с заменой раствора каждые 3 суток; 6 - извлечение зубов из деминерализирующего геля; промывка в дистиллированной воде; погружение (10 с) в кипящую воду для снятия воска

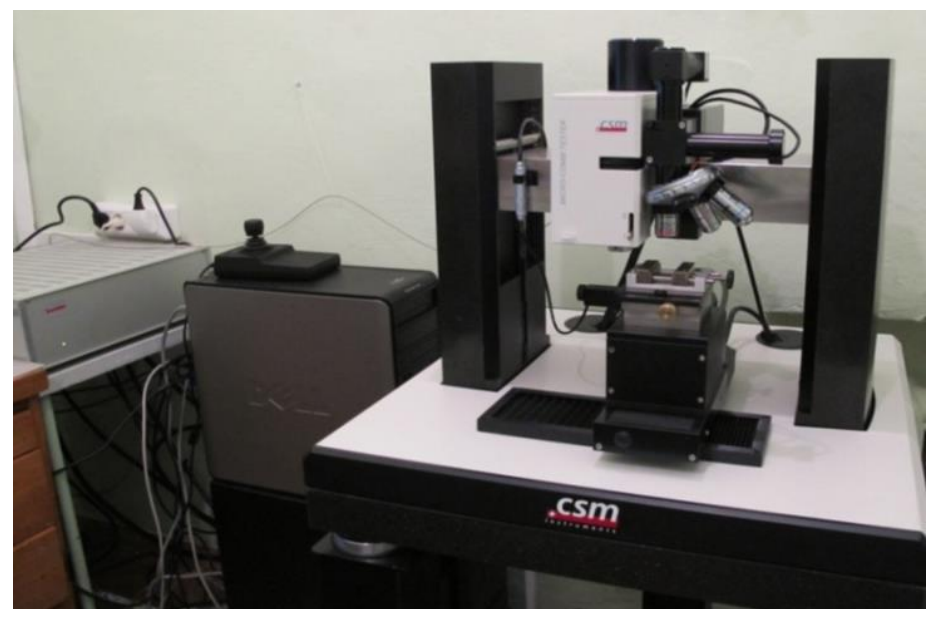

Puc. 2. Установка Micro-combi tester (CSM Instruments SA, Швейцария) для исследования физико-механических свойств биопрепаратов зубов

зионным и датчиками глубины и акустической эмиссии, видеомикроскопом с тремя объективами и CCD камерой прогрессивной развертки (рис. 2). Испытания проводили в соответствии с Международным стандартом ISO 14577, регламентирующим индентирование материала с одновременной регистрацией трех параметров: нагрузки на индентор, перемещения индентора и времени индентирования в процессе упругой и пластической деформации материала.

Объекты исследования - биопрепараты зубов с моделированным ИКЭ, в зависимости от воспроизводимой методики инфильтрационного лечения, рандомизи- 
рованные по трем группам (по 6 биопрепаратов в каждой): первая, в которой для лечения ИКЭ in vitro воспроизведена стандартная методика инфильтрационного лечения (СИЛ), предполагающая этап 2-минутного кондиционирования очага деминерализации перед собственно его инфильтрацией композитом; вторая, модифицированная методика (МСИЛ) - с 4-минутным режимом кондиционирования; и третья, комбинированная методика инфильтрационного лечения (КИЛ), основанная на комбинировании модифицированной по временному режиму кондиционирования эмали методики СИЛ с технологией финишного ламинирования проинфильтрированного кариозного пятна и прилежащей к нему зоны перифокальной эмали защитным биоактивным гибридным стеклоиономером (БГС) многофункционального пролонгированного действия. Кроме того, в отдельной серии исследований (6 биопрепаратов) определяли микротвердость интактной и деминерализованной эмали.

Для всестороннего анализа механизмов лечения кариеса эмали методом КИЛ проводилось микроиндентирование защитного покрытия проинфильтрированной эмали - биоактивного стеклоиономера в пределах 12 мкм, соответствующего толщине ламината. Изучались в сравнительном аспекте физико-механические показатели на шлифах: интактной (I) эмали (неповрежденная зона эмали, не имеющая прямого контакта с очагом деминерализации); на границе перехода интактной (II) эмали в зону деминерализации (перифокальная зона); эмали в центре очага деминерализации; проинфильтрированной эмали по СИЛ-методике; проинфильтрированной эмали по МСИЛ-методике; биоактивного стеклоиономера, нанесенного на вестибулярную поверхность после МСИЛ.

Микроиндентирование деминерализованной эмали, проинфильтрированной светокомпозитом по СИЛ- и МСИЛ-методикам, проводилось в двух зонах на поперечных шлифах (рис. 3): 1) в подповерх-

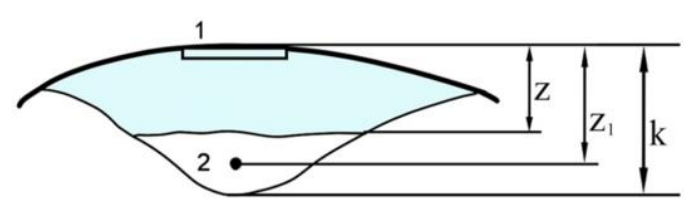

$a$

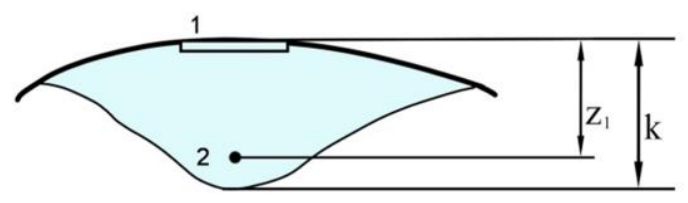

6

Рис. 3. Зонь индентирования проинфильтрированной эмали на поперечном илифе: $а$-СИЛ; б-МСИЛ

ностном слое эмали; 2) на расстоянии $85 \%$ от вестибулярной поверхности в сторону эмалево-дентинной границы, что обеспечивало попадание индентора в переходную, не плотно обтурированную инфильтрантом зону при стандартной методике, рассчитывая по формуле

$$
z_{1}=k \times 0,85 \text { (мкм), }
$$

где $k$ - глубина ИКЭ (определялась по компьютерной томографии); $z$ - глубина заполнения инфильтрантом зоны деминерализованной эмали по стандартной методике (определялась по компьютерной томографии); $z_{1}$ - зона индентирования для стандартной и модифицированной методик.

Биопрепараты трех групп (18 премоляров) прошли исследование на компьютерном томографе для выявления глубины очага ИКЭ и уровня его заполнения инфильтрантом (табл. 1).

Подготовка тестируемых образцов к микроиндентированию: стерилизация и механическая обработка вестибулярной поверхности зуба циркулярной щеточкой и пастой Clinpro Prophy Paste; заливка зуба эпоксидным составом для последующего изготовления шлифов (рис. 4); после шлифования образец промывался в ультразвуковой ванночке. По результатам микроиндентирования анализировались следующие показатели эмали: микротвердость (HIT, ГПа) и модуль упругости (EIT, ГПа). На всех этапах микроиндентирование проводилось с шагом от 10 до 30 мкм в обоих 
направлениях $(\mathrm{X}, \mathrm{Y})$. На каждом объекте го на индентор, составляла $0,5 \mathrm{H}$, что обесисследования проведено 20-40 микроин- печивало микроиндентирование в поверхдентирований в автоматическом режиме ностных слоях эмали. Объем проведенных (рис. 5). Величина усилия, прикладываемо- микроиндентирований - 480 замеров.

Таблийа

Сравнительная оценка глубины заполнения очага ИКЭ светокомпозитом по стандартной, модифицированной и комбинированной методикам инфильтрационного лечения

\begin{tabular}{|c|c|c|c|c|}
\hline № зуба & $\begin{array}{c}\text { Глубина } \\
\text { очага ИКЭ, } \\
\text { мкм }\end{array}$ & $\begin{array}{c}\text { Глубина заполнения } \\
\text { ИКЭ } \\
\text { светокомпозитом } \\
\text { (Z, мкм) }\end{array}$ & $\begin{array}{c}\text { Толщина } \\
\text { непроинффильтрированного } \\
\text { участка, мкм }\end{array}$ & $\mathrm{Z}_{1}=\mathrm{k} \times 0,85$ (мкм) \\
\hline \multicolumn{5}{|c|}{ сил } \\
\hline 1 & 506,0 & 405,8 & 100,2 & 430,1 \\
\hline 2 & 461,1 & 360,1 & 101,0 & 392,0 \\
\hline 3 & 316,4 & 191,1 & 125,3 & 269,0 \\
\hline 4 & 423,8 & 298,0 & 125,8 & 360,2 \\
\hline 5 & 442,3 & 319,3 & 123,0 & 376,0 \\
\hline 6 & 352,1 & 213,4 & 138,7 & 299,3 \\
\hline \multicolumn{5}{|c|}{ мСил } \\
\hline 7 & 513,9 & 513,9 & - & 436,8 \\
\hline 8 & 460,3 & 460,3 & - & 391,0 \\
\hline 9 & 328,3 & 328,3 & - & 279,1 \\
\hline 10 & 409,5 & 409,5 & - & 348,1 \\
\hline 11 & 437,2 & 437,2 & - & 371,6 \\
\hline 12 & 349,9 & 349,9 & - & 297,4 \\
\hline \multicolumn{5}{|c|}{ кил } \\
\hline 13 & 373,3 & 373,3 & - & 317,3 \\
\hline 14 & 477,4 & 477,4 & - & 405,8 \\
\hline 15 & 411,8 & 411,8 & - & 350,0 \\
\hline 16 & 375,9 & 375,9 & - & 319,5 \\
\hline 17 & 464,0 & 464,0 & - & 394,0 \\
\hline 18 & 387,8 & 387,8 & - & 329,6 \\
\hline
\end{tabular}

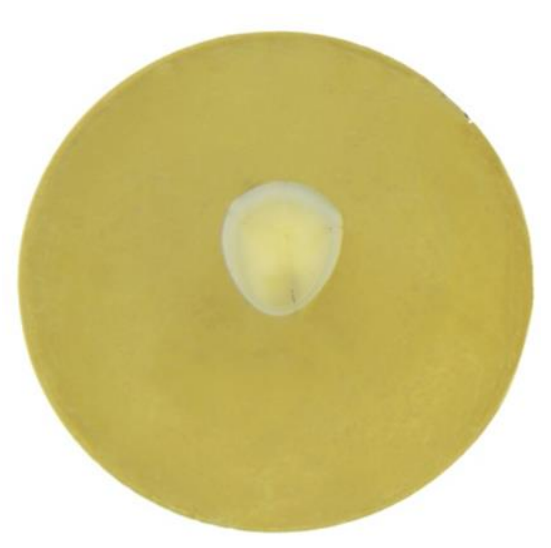

Рис. 4. Поперечный илиф зуба для микроиндентирования

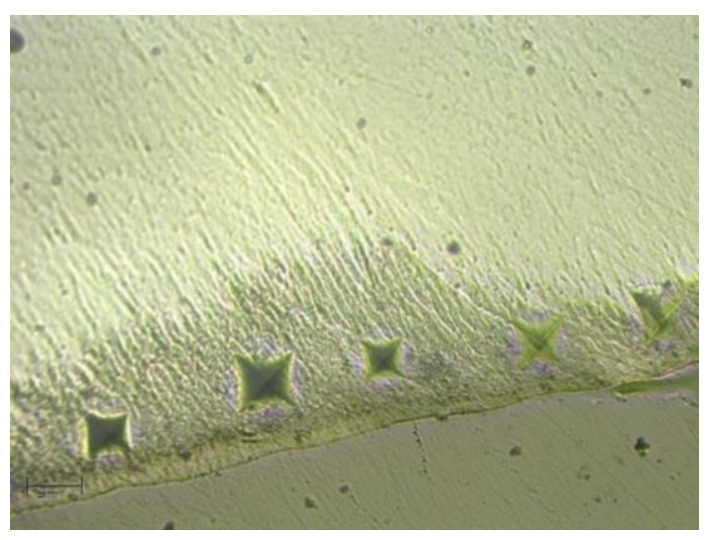

Рис. 5. Микроиндентирование деминерализованной эмали на поперечном шлифе 


\section{Результаты}

Стереомикроскопический анализ увеличенных $(12,5 \times)$ цифровых изображений вестибулярной поверхности премоляров после in vitro воспроизведения ИКЭ свидетельствовал о формировании типичных очагов деминерализации эмали, преимущественно $(75,0 \%)$ квадратной или, реже $(25,0 \%)$, овальной формы (рис. 6). Очаги ИКЭ были лишены присущего интактной эмали блеска и опалесценции, отличались белым цветом, имели четкие границы. При зондировании текстура поверхности
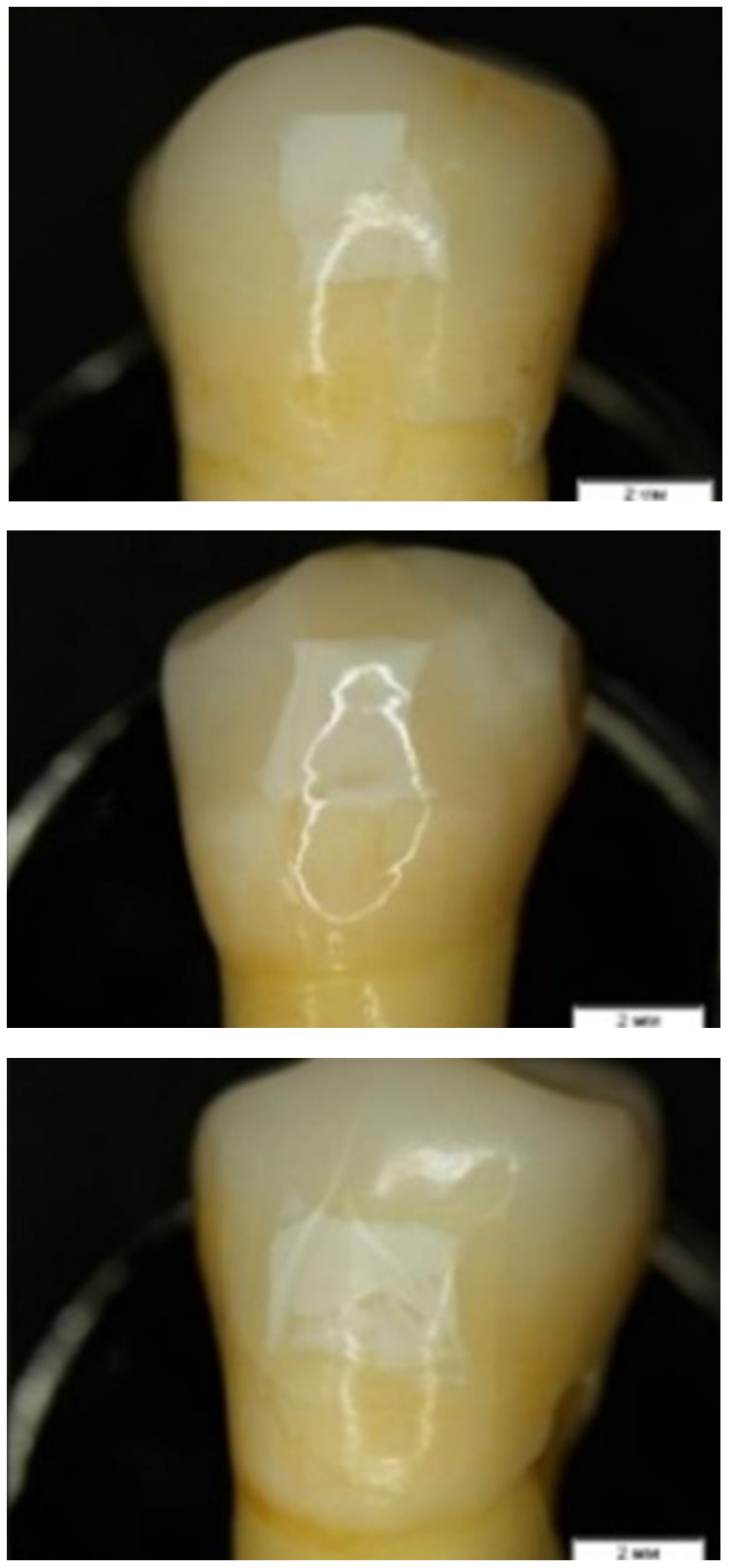

Рис. 6. Очаги ИКЭ на вестибулярной поверхности эмали, воспроизведенные по оригинальной методике абсолютного большинства очагов ИКЭ определялась как неровно-шероховатая. Клинические признаки ИКЭ на поверхности эмали абсолютного большинства тестируемых образцов соответствовали коду K02,0 - по МКБ-10, коду 2 - по ICDAS, т.е. типичным клинико-топографическим и цветотекстурным характеристикам кариеса эмали in vivo, указывало на чувствительность разработанной модели ИКЭ, предопределяло показания к проведению инфильтрационного лечения.

Среднее значение показателей глубины очагов ИКЭ, определяемое с помощью компьютерной томографии, составило $423,8 \pm 107,4$ мкм $(\mathrm{p}>0,05)$. Средняя глубина заполнения деминерализованной эмали инфильтрантом по СИЛ-методике составила 298,0 $\pm 44,5$ мкм $(\mathrm{p}>0,05)$, а средняя толщина участка непроинфильтрированной светокомпозитом деминерализованной эмали - 125,8 $\pm 62,9$ мкм ( $>0,05)$. Глубина заполнения деминерализованной эмали светокомпозитом составила $70,4 \pm 9,8 \%$ (рис. 7 ).

Полученные с помощью высокоточного прибора «Micro-combi tester» зависимости силы нагрузки (Н) и глубины проникновения индентора (мкм) на образцах: интактная (I) эмаль, не имеющая прямого контакта с ОДЭ; граница перехода интактной (II) эмали в зону деминерализации (перифокальная зона); эмаль в центре очага деминерализации; проинфильтрированная светокомпозитом эмаль по методике СИЛ на глубине 85\% в сторону эмалево-дентинной границы; проинфильтрированная светокомпозитом эмаль по методике МСИЛ на глубине $85 \%$ в сторону эма-

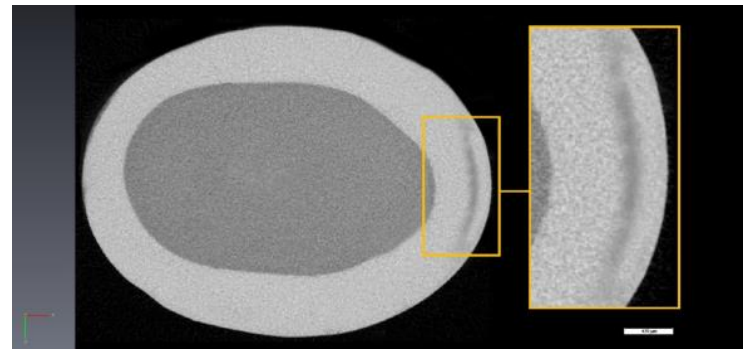

Рис. 7. Аксиальная томограмма 2,4d с участком непроинфильтрированной светокомпозитом деминерализованной эмали 


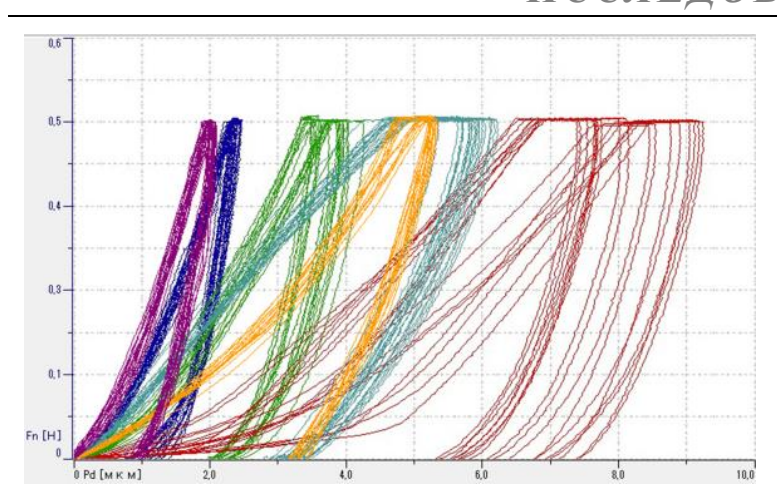

Рис. 8. Диаграмма зависимости глубины проникновения индентора (мкм) от силь нагрузки (H): фиолетовый - интактная (I) эмаль; синий - интактная (II) эмаль; бирюзовый

- эмаль в иеетре очага деминерализачии; оранжевый - проинфильтрированная светокомпозитом эмаль по методике СИЛ на глубине z1 = $k \times 0,85$ мкм; зеленьй - проинфильтрированная светокомпозитом эмаль по методике МСИЛ на глубине $z 1=k \times 0,85$ мкм;

красный - биоактивный стеклочономер на вестибулярной поверхности

лево-дентинной границы; биоактивный стеклоиономер, нанесенный после МСИЛ показаны на рис. 8. Замеры микроиндентирования деминерализованной эмали, проинфильтрированной светокомпозитом по двум методикам (СИЛ и МСИЛ), в подповерхностном слое достоверно не отличались $(\mathrm{p}<0,001)$. Для читаемости и наглядности диаграммы показана разница результатов двух методик, очевидная при замере в зоне проинфильтрированной эмали на глубине $z_{1}=k \times 0,85$ (мкм).

Микротвердость интактной (II) эмали в зоне, перифокальной очагу деминерализации, при воздействии на индентор силой $0,5 \mathrm{H}$ составила $5,01 \pm 0,54$ ГПа, а средняя глубина проникновения 2,38 мкм, что достоверно $(\mathrm{p}<0,05)$ ниже в сравнении с показателями микротвердости интактной (I) эмали $(5,86 \pm 0,25$ ГПа; 1,92 мкм) в отдаленных от ОДЭ участках.

Микротвердость деминерализованной эмали составила 0,956 $\pm 0,015$ ГПа (средняя величина проникновения индентора 6,2 мкм) была достоверно сниженной $(\mathrm{p}<0,01)$ в сравнении с показателями интактной эмали как в перифокальных, так и в отдаленных от ОДЭ зонах.
Микротвердость в подповерхностных слоях деминерализованной эмали, проинфильтрированной светокомпозитом по СИЛ (HIT $=1,95 \pm 0,17$ ГПа) и МСИЛ $(\mathrm{HIT}=1,98 \pm 0,15$ ГПа) методикам достоверно не отличалась ( $<<0,001)$, а на глубине $z_{1}=k \times 0,85$ (мкм) при воспроизведении стандартной методики была незначительно (в 1,3 раза) выше $(\mathrm{p}<0,05)$ показателя деминерализованной эмали и составила $1,21 \pm 0,36$ ГПа, а средняя величина проникновения индентора - 5,0 мкм и, кроме того, показатели микротвердости были достоверно $(\mathrm{p}<0,01)$ в $4,0-4,8$ раза снижены в сравнении с показателями интактной эмали (II, I) соответственно.

Микротвердость деминерализованной эмали, проинфильтрированной светокомпозитом по методике МСИЛ, на глубине $z_{1}=k \times 0,85$ (мкм) в сравнении с показателями деминерализованной эмали возрастала в 2 раза до $1,930 \pm 0,40$ ГПа, а средняя величина проникновения индентора составила 3,8 мкм, микротвердость также превышала $(\mathrm{p}<0,05)$ значения после проведения стандартной методики в 1,6 раза, но была достоверно $(\mathrm{p}<0,01)$ сниженной в сравнении с показателями интактной эмали (II, I), соответственно в 2,6 и 3,0 раза.

Микротвердость биоактивного стеклоиономера, нанесенного на поверхность деминерализованной эмали после МСИЛ (комбинированная методика), составила 0,366 $\pm 0,090$ ГПа, а средняя величина проникновения индентора - 7,7 мкм, что в 5,3 раза ниже $(\mathrm{p}<0,01)$ показателя микротвердости деминерализованной эмали после МСИЛ.

Модуль упругости интактной (II) эмали составил $83,8 \pm 14,4$ ГПа и был незначительно ниже $(\mathrm{p}<0,05)$ в сравнении с показателями интактной (I) эмали $(85,4 \pm 6,6$ ГПа), проиндентированной в отдаленных от ОДЭ участках.

Модуль упругости деминерализованной эмали составил 10,34 $\pm 1,35$ ГПа, что достоверно ниже $(\mathrm{p}<0,001)$ показателей интактной (I,II) эмали.

Модуль упругости деминерализованной эмали, проинфильтрированной све- 
токомпозитом по методике СИЛ, был достоверно выше $(\mathrm{p}<0,01)$ такового у деминерализованной эмали и составил 20,26士4,12 ГПа, но был достоверно в 4,2 раза - снижен $(\mathrm{p}<0,01)$ в сравнении с показателями интактной (I,II) эмали.

Модуль упругости деминерализованной эмали, проинфильтрированной светокомпозитом по методике МСИЛ, был достоверно - в 1,7 раза - выше показателя эмали после воспроизведения стандартной инфильтрации и составил $33,8 \pm 12,0$ ГПа, но в сравнении с показателями интактной (I, II) эмали был достоверно $(\mathrm{p}<0,05)-$ в 2,5 раза - более низким.

Модуль упругости биоактивного стеклоиономера, нанесенного после кариес-инфильтрачии, составил 10,3土1,6 ГПа, был в 3,3 раза более низким $(\mathrm{p}<0,05)$, чем у показателей эмали, проинфильтрированной по методике МСИЛ.

\section{Заключение}

Результаты исследования физикомеханических свойств интактной (I,II) эмали характеризуют её как высокопрочный и высокоупругий биоматериал $\left(\mathrm{HIT}_{\mathrm{I}}=5,86 \pm 0,25\right.$ ГПа, $\mathrm{EIT}_{\mathrm{I}}=85,4 \pm 6,6$ ГПа; НІТ $_{\text {II }}=5,006 \pm$ $\pm 0,540$ ГПа, EIT $_{\text {II }}=83,8 \pm 14,4$ ГПа coответственно), способный выдерживать направленные деформационные нагрузки при функционировании зубочелюстной системы. Анализ полученных данных показывает, что интактная эмаль по микротвердости укладывается в характеристики конструкционых сталей с поверхностной цементацией, а модуль упругости сравним с показателями деформационных алюминиевых сплавов.

В ходе исследований методом микроиндентирования получены новые, ранее не изученные данные о микротвердости (НIT, ГПа) и модуле упругости (EIT, ГПа) деминерализованной эмали, проинфильтрированной светокомпозитом по методикам СИЛ и МСИЛ, в поверхностном слое и на глубине $85 \%$ в сторону эмалеводентинной границы.
Показатели микротвердости в

подповерхностных слоях деминерализованной эмали, проинфильтрированной светокомпозитом по стандартной $(\mathrm{HIT}=1,95 \pm 0,17$ ГПа) и модифицированной $(\mathrm{HIT}=1,98 \pm 0,15$ ГПа) методикам, достоверно не отличались $(\mathrm{p}<0,001)$, а на глубине $85 \%$ в сторону эмалево-дентинной границы по СИЛ $\quad(\mathrm{HIT}=1,21 \pm 0,36$ ГПа) и МСИЛ $(\mathrm{HIT}=1,93 \pm 0,40$ ГПа) методикам достоверно $(\mathrm{p}<0,05)$ отличались. Это подтверждает факт неполной обтурации микропор на глубине $\mathrm{z}_{1}=k \times 0,85$ (мкм) и ниже, указывает на отсутствие в межпризменных пространствах эмали упрочняющей матрицы из жидкотекучего композита после её инфильтрации по методике СИЛ. Полученные данные со всей очевидностью объективизируют преимущества методики МСИЛ перед классической инфильтрационной технологией лечения кариеса эмали. Вместе с тем обосновать преимущества комбинированного инфильтрационного лечения по этому направлению исследований не представлялось возможным в связи с идентификацией сравнительно невысоких микромеханических характеристик собственно БГС-покрытия эмали, применение которого предусмотрено этой методикой.

Эти результаты вполне прогнозируемы и неспособны опровергнуть патогенетическую ценность комбинированного инфильтрационного лечения, так как использование в его алгоритме этапа финишного ламинирования очага ИКЭ и его перифокальной зоны слоем защитного стеклоиономера не ставит задачу повышения микротвердости проинфильтрированной эмали, облегчения диффузии инфильтранта и полной обтурации микропор в очаге поражения. Комбинированное инфильтрационное лечение направлено на сглаживание шероховатого рельефа поверхности очага деминерализации, создание защитного механического покрытия эмали, формирование барьера для проникновения кариесогенных микроорганизмов и 
их метаболитов в ее подлежащие слои, а также на проявление пролонгированного реминерализирующего действия БГС-по- крытия за счет выделения ионов фтора, кальция, фосфатов на протяжении всего периода его нахождения в средах ПР.

\section{Библиографический список}

1. Беляев А.Ю. Исследование механических свойств здоровой и поврежденной кариесом зубной эмали с помощью микроиндентирования / А.Ю. Беляев, О.С. Гилева, М.А. Муравьева, А.Л. Свистков, А.П. Скачков // Российский журнал биомеханики. - 2012. - Т. 16. - № 3. - С.57-64.

2. Беляев А.Ю. Модель изменения упругих свойств зубной эмали под действием различных факторов / А.Ю. Беляев, О.С. Гилева, Е.С. Ерофеева, М.А. Муравьева, А.Л. Свистков // Вестник Пермского университета. Серия: Математика. Маханика. Информатика. - 2011. - № 5 (9). - С. 25-28.

3. Гилева О.С. Вычислительное моделирование начальной стадии кариеса зубов: геометрическое моделирование зуба / О.С. Гилева, М.А. Муравьева, Н.И. Симакина, А.К. Соколов, В.Н. Терпугов // Вестник Пермского университета. Серия: Математика. Механика. Информатика. - 2012. Выпуск 2 (10). - С. 20-25.

4. Гилева О.С. Комплексный подход к оценке эстетико-функциональных результатов кариесинфильтрации при лечении кариеса эмали / О.С. Гилева, М.А. Муравьева, Е.В. Серебренникова // Современные проблемы науки и образования. - 2013. - № 2. - С. 61.

5. Гилева О.С. Консервативно-профилактическая стоматология: современные тренды развития // Пермский медицинский журнал. - 2018. - Т. 35. - № 6. - С. 61-72.

6. Гилева О.С. Многоуровневый анализ микроструктуры эмали в обосновании микроинвазивных технологий лечения очаговой деминерализации эмали у пациентов ортодонтического профиля / О.С. Гилева, А.Д. Левицкая, Е.С. Сюткина, И.Н. Халявина // Эндодонтия Тоday. - 2019. - Т. 17. № 3. - C. 17-20.

7. Гилева О.С. Постортодонтическая деминерализация эмали: клинические особенности и эффективность / О.С. Гилева, М.А. Муравьева, Е.С. Сюткина, А.Д. Левицкая // Маэстро стоматологии. - 2015. - № 4. - С. 38-46.

8. Гилева О.С. Экспериментальное исследование поверхности эмали зуба при различных лечебнопрофилактических воздействиях / О.С. Гилева, М.А. Муравьева, А.Л. Свистков, Р.И. Изюмов, А.Д. Левицкая // Вестник Пермского научного центра УрО РАН. - 2017. - № 3. - С. 15-21.

9. Гилева О.С. Экспериментально-клиническая оценка эффективности применения различных методов лечения очаговой деминерализации эмали / О.С. Гилева, А.Д. Левицкая, Е.С. Сюткина, С.В. Коротин, Н.В. Гибадуллина, А.Л. Свистков // Современные проблемы науки и образования. 2018. - № 6. - С. 99.

10. Изюмов Р.И. Биомеханическое моделирование процедуры кариес-инфильтрации фотополимера в зубную эмаль / Р.И. Изюмов, А.Л. Свистков, О.С. Гилева, М.А. Шакуля, А.Д. Левицкая // Российский журнал биомеханики. - 2017. - Т. 21. - № 4. - С. 351-364.

11. Левицкая А.Д. Экспериментальная оценка проникающей способности жидкотекучего композита в деминерализованную эмаль / А.Д. Левицкая, О.С. Гилева, Р.И. Изюмов, Е.С. Сюткина // Dental Forum. - 2019. - № 4. - С. 56-57.

12. Морозов И.А. Экспериментальное исследование влияния клинического отбеливания на микроструктуру поверхности эмали зубов / И.А. Морозов, А.Л. Свистков, О.С. Гилева, E.C. Ерофеева // Российский журнал биомеханики. - 2010. - Т. 14. - № 14. - № 1. - С. 56-64.

13. Belyaev A.Y. Experimental studies of elastic properties of dental enamel and photopolymer used for early caries treatment / A.Y. Belyaev, A.L. Zuev, O.S. Gileva, M.A. Muraveva // Key Engineering Materials. 2014. - Vol. 592-593. - P. 358-361.

14. Kielbassa A.M. Ex vivo investigation on internal tunnel approach/internal resin infiltration and external nanosilver-modified resin infiltration of proximal caries exceeding into dentin / A.M. Kielbassa, M.R. Leimer, J. Hartmann, S. Harm, M. Pasztorek, I.B. Ulrich // PLoS One. - 2020. - Vol. 28, № 15(1). Art. id. e0228249.

15. Levitskaya A. The combined approach to evaluation of mechanical behavior of tooth enamel in artificially induced caries lesions / S. Galkin, A. Levitskaya, O. Gileva, T. Libik, L. Lomiashvili // BIO Web of Conferences. - 2020. - Vol. 22. - P. 2-9.

16. Meyer-Lueckel H. Kariesinfiltration - Update 2017. / H. Meyer-Lueckel, S. Paris, A. Schult // Zahnmedizin up2date. - 2017. - Vol. 11 (03). - P.267-290.

17. Paris S. Infiltrants inhibit progression of natural caries lesions in vitro / S. Paris, H. Meyer-Lueckel // J. Dent. Res. - 2010. - Vol. 89. - P. 1276-1280. 
18. Perdigão J. Resin infiltration of enamel white spot lesions: An ultramorphological analysis // J. Esthet. Restor. Dent. - 2020. - Vol. 32. - № 3. - P. 317-324.

19. Skucha-Nowak M. Assessing the Penetrating Abilities of Experimental Preparation with Dental Infiltrant Features Using Optical Microscope: Preliminary Study / M. Skucha-Nowak, A. Machorowska-Pieniażek, M. Tanasiewicz // Advances in Clinical and Experimental Medicine. - 2016. - Vol. 25 (5). - P. 961-969.

\title{
THE STUDY OF PHYSICAL AND MECHANICAL PROPERTIES OF TOOTH ENAMEL USING KINETIC MICROINDENTATION
}

\author{
O.S. Gileva ${ }^{1}$, A.D. Levitskaya ${ }^{1}$, A.L. Zuev ${ }^{2}$ \\ ${ }^{1}$ Perm State Medical University named after E.A. Wagner \\ ${ }^{2}$ Institute of Continuous Media Mechanics UB RAS
}

For citation:

Gileva O.S., Levitskaya A.D., Zuev A.L. The study of physical and mechanical properties of tooth enamel using kinetic microindentation // Perm Federal Research Center Journal. - 2021. - № 1. - P. 37-46. https://doi.org/10.7242/2658-705X/2021.1.3

The work carried out a comparative assessment of the physical and mechanical properties of tooth enamel that was healthy, demineralized, demineralized and subsequently infiltrated with a fluid composite according to a standard, modified and combined technique, completed by the lamination of the infiltrated enamel with a bioactive hybrid glass ionomer. An original in vitro model of artificial caries of human enamel was used for the study, its clinical-topographic and color-textural physical and mechanical properties correspond to the characteristics of enamel caries in vivo. Comparative analysis of the results of kinetic microindentation of enamel samples allows us to characterize the biomaterial from the standpoint of physical materials science, to determine the advantages and disadvantages of various technological options for the infiltration treatment of caries (focal demineralization) of enamel.

Keywords: focal demineralization of enamel, artificial enamel caries, infiltration treatment, microindentation of enamel, microhardness, elastic modulus.

\section{Сведения об авторах}

Гилева Ольга Сергеевна, доктор медицинских наук, профессор кафедры терапевтической стоматологии и пропедевтики стоматологических заболеваний, ФГБОУ ВО «Пермский государственный медицинский университет имени академика Е.А. Вагнера» Минздрава России («ПГМУ им. академика Е.А. Вагнера Минздрава России»), 614990, г. Пермь, ул. Петропавловская, 26; e-mail: o.s.gileva@yandex.ru

Левиџкая Анна Дмитриевна, ассистент кафедры терапевтической стоматологии и пропедевтики стоматологических заболеваний, «ПГМУ им. академика Е.А. Вагнера Минздрава России»; e-mail: smehach713@mail.ru

Зуев Андрей Леонидович, доктор физико-математических наук, доцент, старший научный сотрудник, Институт механики сплошных сред УрО РАН - филиал Пермского федерального исследовательского центра УрО РАН («ИМСС УрО РАН»); 614013, г. Пермь, ул. Академика Королева, 1; e-mail: zal@icmm.ru 